\title{
On The Possibility of Knowledge Through Unsafe Testimony
}

\author{
B.J.C. Madison
}

(Forthcoming in Social Epistemology)

Draft Version - Do Not Cite Without Approval

\begin{abstract}
If knowledge requires safety, then one might think that when the epistemic source of knowledge is testimony, that testimony must itself be safe. Otherwise, will not the lack of safety transfer from testimony to hearer, such that hearer will lack knowledge? Resisting this natural line of reasoning, Goldberg $(2005 ; 2007)$ argues that testimonial knowledge through unsafe testimony is possible on the basis of two cases. Lackey (2008) and Pelling (2013) criticize Goldberg's examples. But Pelling goes on to provide his own example that attempts to show that Goldberg's thesis is true: one can gain safe testimonial belief from unsafe testimony. If any of these counterexamples were correct, they would undermine the main reason to think that knowledge based on unsafe testimony is impossible. My aim in this paper is to critically assess these arguments, and to consider the possibility of knowledge through unsafe testimony. Drawing a general moral from the analysis of these cases, I shall contend that it is impossible to acquire safe belief solely on the basis of unsafe testimony. If so, then testimonial knowledge based solely on unsafe testimony is impossible.
\end{abstract}

Key Words: Knowledge; Testimony; Safety.

\section{Introduction:}

It is widely held that knowledge is a state that must in some sense be nonluckily true ${ }^{1}$. If one gains a true belief in a way that involves too much of certain kinds of luck, then no matter what else the belief has going for it, it does not amount to knowledge. One might think that this is one of the central lessons of the Gettier problem. While there are different ways of trying to make precise the notion of luck at play in Gettier cases, one popular and influential proposal for spelling out what this

\footnotetext{
${ }^{1}$ This is widely, though not universally, held. For defences of the idea that there can be lucky knowledge, and indeed knowledge in Gettier cases, see for example the work of Stephen Hetherington. For an early expression of his Knowing Lucky proposal, see Hetherington (1998); for a reply, see Madison (2011). Hetherington (2013) and Pritchard (2013) debate whether knowledge is incompatible with luckily true belief. Hetherington (2016) is his latest and most detailed response to the anti-luck tradition in contemporary epistemology.
} 
anti-luck condition amounts to is in terms of safety. Very roughly, a belief is safe if, given how it is formed, it could not have easily been false. According to this proposal, safety is taken to be a necessary condition on knowledge in general, regardless of its source.

If knowledge requires safety, then one might think that when the epistemic source of knowledge is testimony, that testimony must itself be safe. Otherwise, will not the lack of safety transfer from testimony to hearer, such that hearer will lack knowledge? Resisting this natural line of reasoning, Goldberg $(2005 ; 2007)$ argues that testimonial knowledge through unsafe testimony is possible on the basis of counterexamples. Lackey (2008) and Pelling (2013) criticize Goldberg's examples. But Pelling goes on to provide his own example that attempts to show that Goldberg's thesis is true: one can gain safe testimonial belief from unsafe testimony. If any of these counterexamples were correct, they would undermine the main reason to think that knowledge based on unsafe testimony is impossible.

My aim in this paper is to critically assess these arguments, and to consider the general possibility of knowledge through unsafe testimony. I shall criticize Goldberg's examples, but for different reasons than Lackey and Pelling. I shall also argue that, despite initial appearances to the contrary, Pelling's example suffers from the same defects as Goldberg's. Drawing a general moral from the analysis of these cases, I shall contend that it is impossible to acquire safe belief solely on the basis of unsafe testimony. If so, then testimonial knowledge based solely on unsafe testimony is impossible.

Before proceeding, it is worth pausing to ask: what is the significance of the question of whether or not one can gain knowledge through unsafe testimony? At least one answer immediately presents itself: if safety is a necessary condition on 
knowledge, but safe testimony is not necessary for someone to acquire knowledge via testimony, then this would show that testimony can generate knowledge, rather than always merely transmit knowledge that someone else already possesses. While Jennifer Lackey, for one, has prominently argued for the view that testimony can generate knowledge, her arguments do not turn on the issue of safety (e.g. Lackey 1999; Lackey 2008). Therefore, if knowledge on the basis of unsafe testimony is possible, it would provide an additional independent line of argument against the position that testimony merely transmits knowledge, rather than being a generative source. In short, in addition to the intrinsic epistemological interest of the question of whether testimonial knowledge requires a safe basis, answering this question can shed light on the nature of testimony in general.

\section{The Safety Condition:}

So what is safety? Safety is normally introduced as one way of spelling out the sense in which knowledge must be non-lucky ${ }^{2}$. The exact formulation of safety is not a trivial matter, but when talking about the safety of beliefs, the intuitive idea is that a true belief is safe just in case it could not have easily been false. Somewhat more precisely: to say that a belief is safe is to say that not only is the belief actually true, but in all nearby worlds where the subject forms the belief in the same way as in the actual world, the belief is still true $\mathrm{e}^{3}$. For example, suppose I believe that I have

\footnotetext{
${ }^{2}$ A rival way of attempting to capture the sense in which knowledge is non-lucky is in terms of Sensitivity. A belief that $p$ is sensitive when, if $p$ were false, one would not believe that $p$. A sensitive belief is one that tracks the truth, so to speak. Prominent advocates of a sensitivity condition on knowledge include Dretske (1970); Nozick (1981). For a recent collection of papers on the sensitivity condition in epistemology, see Becker and Black (2012).

${ }^{3}$ What is it to form a belief in the same way in other worlds? Questions about generality and the individuation of belief forming methods and bases immediately arise. This issue is familiar from discussions of the 'generality problem' for reliabilist theories of epistemic justification. See Conee and Feldman (1998) for an early and influential presentation of this objection against reliabilism. The problem, in outline, is this: a token method or way of forming true beliefs is an instance of a more general type of method that can be more or less reliable. However, which types of methods are the
} 
hands on the basis of seeing my hands. Assuming that everything is normal and as it appears, that belief is safe since, not only is the belief true, but given its basis, that belief could not easily be false. In all nearby worlds where I believe that I have hands because I see that I do, that belief is still true. I am not infallible of course, but for that belief to be false given that it is based on how things appear, things would have to very different than they actually are. For example, in those worlds I would be hallucinating, or more radical still, the deceived victim of an evil demon. The thought is that since these are remote possibilities, they do not undermine my belief that I have hands being safely true.

In order to avoid counterexamples, it is important to note in general, and for our discussion of testimonial belief in particular, that safety must be relativized to methods or bases. To modify an example of Nozick's in discussing a sensitivity condition on knowledge, suppose that I see my daughter and thereby come to know that she does not have a cold. Compare that to a case where I instead call my wife and ask how our daughter is, and I am told she is healthy and well. But suppose also that in the second case, given that my wife does not like me to worry, she would have told me on the phone that our daughter did not have a cold, even if she did. Suppose finally that while I in fact saw my daughter, I very easily could have not seen her, and so would in those close worlds have phoned my wife to ask after our daughter.

Seemingly, the fact that I could have very easily formed a false belief in the second case is not relevant to whether or not I have knowledge in the first case.

relevant ones here? A process type can be individuated more or less finely, with the associated reliability varying widely. For example, when I form a belief about the presence of a mug on the table before me, which method am I using? Is it perception, or visual perception, or visual perception in good lighting, etc.? Some of these methods are far more reliable than others, and yet the charge is that it is difficult (if not impossible) to non-arbitrarily say which method is the one whose reliability is relevant to whether or not epistemic justification obtains, or in this case, to whether or not a belief is safely formed. A complete theory of safety will require a solution to the generality problem, but providing such an account is outside the scope of this paper. For some recent responses that have tried to solve the generality problem, see for example Heller (1995); Beebe (2004); Comesana (2006); Becker (2008). 
This highlights that the issue is not whether I could have easily had a false belief about my daughter's health, but whether or not I could have easily been wrong, given the basis of my belief. So where the basis of belief is my seeing her, that belief is safe, and constitutes knowledge, whereas when the basis of my belief is phoning my wife in the circumstances described, that belief is not safe, and so does not amount to knowledge even if true, given that my belief could have very easily been false formed on that basis.

Safety is most often introduced in the context of discussing the sense in which beliefs can be non-lucky, but following Charlie Pelling, we can define an analogous notion of Safe Testimony: 'Where one testifies that $p$ on basis $B$, one's testimony is safe just if there is no close possibility in which one falsely testifies that $p$ on $B$.' (Pelling, 2013, p. 209) So if my wife testifies that our daughter is healthy and well on the basis of seeing that she is, that testimony is safe just if there is no close possibility in which she falsely testifies that our daughter is healthy and well on the basis of how she appears.

For the purposes of this paper, I shall assume that knowledge requires safety. But I trust that this is not a groundless assumption. What motivates safety? Briefly, safety is motivated by the theoretical work it can do in at least two different central debates in epistemology. First, safety has been proposed as part of the analysis of knowledge and as a response to the Gettier problem. For example, a failure of safety has been proposed as a diagnosis of why Gettier cases arise, and since a Gettiered belief is not knowledge, safety has been proposed as a necessary condition on knowledge (e.g. see Pritchard 2005; Pritchard 2015).

A second motivation for the safety principle is the work it is meant to do as a key premise in Neo-Moorean responses to radical skepticism (e.g. see Sosa 1999; 
Pritchard 2005; Pritchard 2007). According to the Neo-Moorean, given that relying on one's perceptual experiences can be a safe way of forming true beliefs about the external world, this is meant to provide part of the theoretical explanation that Moore himself failed to provide in his infamous 'proof' of the external world.

So with the notions of safe belief and safe testimony to hand, and the assumption that knowledge requires safety, we can now explore our central question: when a belief that $p$ is formed on the basis of testimony, must this testimony be safe for the testimony-based belief to become knowledge that $p$ ?

\section{Goldberg's Examples}

Sanford Goldberg $(2005 ; 2007)$ offers two cases in support of the claim that testimonial knowledge through unsafe testimony is possible. We shall consider each of his examples in turn. The first case is the following:

Goldberg's First Case - MILK CARTON: Frank is a writer who spends his mornings in the kitchen, where he follows a mildly eccentric ritual. Every day after finishing his bowl of cereal at around dawn, he discards whatever milk is left, but places the empty carton back in the fridge, where it remains until noon, when he takes out the trash. Today, his sister Mary and nephew Sonny are visiting. Having had a tiring journey, they sleep in and join Frank in the kitchen in the late morning. Mary sees the milk carton in the fridge, assumes it is full, and on that basis tells Sonny that there is milk in the fridge. As it happens, there is indeed milk in the carton this morning, since Frank forgot to perform his ritual. Upon overhearing Mary's testimony, Frank is reminded of his blunder and realizes that he forgot to discard of the milk this morning; at the same moment, Sonny, on the basis of his mother's testimony, forms the belief that there is milk in the fridge. Had Frank performed his ritual, he would have immediately corrected Mary and would have informed his visitors that the carton was empty. (Gelfert, 2014, p. 156, which paraphrases and simplifies Goldberg 2005 p. 302)

Commenting on the case, Goldberg (2005), Jennifer Lackey (2008, ch. 3.3), and Charlie Pelling (2013, pp. 210-212) all say that Mary's testimony is unsafe: although her statement that there is milk in the fridge is true, it could have easily been false, namely in the close worlds where Frank performs his milk dumping ritual. But 
Goldberg argues that despite Mary's unsafe testimony, Sonny's belief is safe. This is because there are no nearby worlds where Sonny forms his belief on the basis of Mary's testimony and it is false, since in all those worlds, Frank is 'silently monitoring' (as Lackey and Pelling describe his contribution) and would correct Mary's testimony. In those cases, Sonny would not form the false belief that there is milk in the fridge.

Lackey presents Goldberg with a dilemma (which Pelling also endorses): either Sonny's belief is unsafe or else it is not wholly based on testimony (Ibid.). Arguing for the first horn of the dilemma, Lackey contends that Sonny's belief is unsafe since temporal order matters: at the moment when he forms his belief, it is solely based on Mary's unsafe testimony, and so it is unsafe. It is only after Sonny forms the belief that Frank's monitoring kicks in (even if only seconds later). As for the second horn of the dilemma, Sonny's belief might then become safe, after uncle Frank's silent monitoring begins, but now his belief is no longer based solely on Mary's testimony. At this later time, Sonny's belief is now based on two things: Mary's testimony, plus Frank's silent monitoring.

Why, according to Lackey and Pelling, does Sonny's belief when safe not count as properly testimonial? This is because they both endorse a very strict notion of testimonial belief. Pelling, citing Lackey, writes that 'a belief does not count as testimonial if, though causally dependent on an act of testimony, it depends for its epistemic credentials on a non-testimonial act.' (emphasis added) (Pelling, 2013, p. 211; cf. Lackey, 2008, p. 84) A consequence of this is that, for a belief to count as testimonial, it must be epistemically grounded exclusively on an act of testimony. The thought is that if Sonny's belief amounts to knowledge, an element of its epistemic credentials, that is, part of that which helps convert his true belief into knowledge, is 
something non-testimonial. If Sonny's belief amounts to knowledge, this is because not only is his belief supported by Mary's testimony, but also because his belief is safe, which in turn depends essentially on Frank's so-called silent monitoring - a factor which is not itself testimonial. So, they contend, Sonny's belief is not testimonial.

One might wonder: is this not a very narrow and strict notion of what counts as a testimonial belief? If it is employed, is there any purely testimonial belief in this sense? I take that to be an open question, one which I intend my discussion to answer (section 5 below presents my full answer to this question). In addition, some further comments are in order. First, Lackey and Pelling implicitly rely upon this notion of testimonial belief in their respective discussions. Accordingly, I propose that we accept it as part of the terms of the debate.

Second, and even more importantly, as Pelling notes (2013, section 2.2), it is only on a very strict notion of testimonial belief that the epistemologically interesting question of whether there can be safe testimonial belief on the basis of unsafe testimony arises. This is the interesting question, since the question of whether one can gain safe testimonial belief, when it is based only partly on unsafe testimony, is answered trivially. As Lackey and Pelling both note, obviously one can gain a safe belief that is partly based on unsafe testimony and partly based on other (safe) sources, like one's own perception, or memory, or other non-testimonial sources.

To see this, let us distinguish Strict from Liberal conceptions of testimonial belief as follows:

Strict Conception of Testimonial Belief: for a belief that $p$ to count as testimonial, it must depend for its epistemic status exclusively on an act of testimony. 
Liberal Conception of Testimonial Belief: for a belief that $p$ to count as testimonial, it must partly depend for its epistemic status an act of testimony, and partly depend for its epistemic status on something non-testimonial. ${ }^{4}$

It is only on a strict conception of testimonial belief that we would get interesting and novel philosophical results of the sort that Goldberg and Pelling aim to establish. This is because on the Liberal Conception of Testimonial belief, the answer to the question of whether there can be safe testimonial belief in that sense, on the basis of unsafe testimony, is straightforward. As Pelling himself illustrates,

[...] if we use the more liberal conception, it becomes fairly easy to establish that one can gain safe testimonial belief from unsafe testimony. For example, consider the following:

RED BARN: John phones me to say that he can see a (real) red barn. Although John's testimony is true, it might easily have been false. For unbeknown to him the area contains many fake barns which until yesterday were painted red. However, I happen to know that all the fakes have now been repainted blue: the only remaining red barn in the area is real. I thereby come to believe, partly on the basis of John's testimony and partly on the basis of my background knowledge, that John can see a red barn.

In this case, it seems that although John's testimony is unsafe, the belief I form partly on the basis of that testimony is safe. So if we allow my belief to count as 'testimonial', in virtue of its partly testimonial basis, then the case seems straightforwardly to confirm that one can gain safe testimonial belief from unsafe testimony. (Pelling, 2013, p. 209)

For these reasons, then, the Strict Conception of Testimonial Belief will be assumed when investigating the possibility of testimonial knowledge through unsafe testimony.

I agree with Lackey and Pelling that Goldberg's first example faces the dilemma that either Sonny's belief is unsafe, or else it is not a testimonial belief, strictly so-called, and so it is not a counterexample to the claim that testimonial knowledge requires safe testimony. But I suggest that we should reject Pelling and Lackey's focus on non-testimonial acts in accounting for whether a belief should be

\footnotetext{
${ }^{4}$ Thank you to an anonymous referee for this journal for noting that the choice between strict and liberal conceptions of testimonial belief will in part depend upon one's position in the reductionism / non-reductionism debate in the epistemology of testimony. For a discussion of the distinction between reductionism and non-reductionism about testimonial knowledge, see for example Lackey (2006) pp.46.
} 
counted as purely testimonial. If MILK CARTON is not a case of a purely testimonial belief because of Frank's contribution, which I agree that it is not, this is not because of any non-testimonial act on Frank's part. This, I suggest, is because there is no relevant act on Frank's part at all.

Lackey and Pelling describe Frank as silently monitoring the situation. Assuming for a moment that this is a correct description, is silent monitoring itself an act? It might seem more like a passive state in which one can acquire information. But even if silent monitoring is in general an action, is that really what Frank is doing in this case? After all, he is not actively attending to the situation, nor is he intending to listen out for errors. For that matter, there is nothing that he is trying to do related to either Mary's testimony or Sonny's beliefs. He simply overhears Mary, and at that point is reminded that he forgot to perform his milk-dumping ritual. Overhearing something, and being reminded of something, are not actions either. At that point, there is no relevant act on Frank's part, but the following counterfactual is now true: had he performed his ritual, he would have immediately corrected Mary, and he would have informed his visitors that the carton was empty. And Frank's presence in this situation, something non-testimonial, is now partly the source of the epistemic credentials of Sonny's belief.

So while Lackey and Pelling are right that Sonny's belief is not purely testimonial in the strict sense that they are interested in, this not because it depends for its epistemic credentials on a non-testimonial act. Rather, it is a non-testimonialsomething that is partly the source of Sonny's belief's epistemic credentials: here it is Frank's presence and what he would do if he were to hear Mary speak falsely. I suggest that in order to capture why Sonny's belief should not be thought of as purely testimonial, we need to move from focusing narrowly on non-testimonial acts, to: 
Testimonial Belief: a belief does not count as testimonial if it depends for its epistemic credentials (i.e. its positive epistemic status) on something non-testimonial.

In addition to allowing us to diagnose why Sonny's belief is not purely testimonial, this notion of testimonial belief will also allow us to see why Goldberg's example of YANKEE FAN, discussed below, is arguably not a case of testimonial belief in the relevant sense either, if it is indeed safe.

I would like to now raise an additional worry about MILK CARTON, which challenges the assumption that Goldberg, Lackey, and Pelling all share: that Mary's testimony is actually unsafe. As noted above, each holds that Mary's testimony is unsafe since although her statement that there is milk in the fridge is true, it could have easily been false, namely in the close worlds where Frank performs his milk dumping ritual.

But notice that the very thing that makes Sonny's belief safe also makes Mary's testimony safe, namely, Frank's presence. Frank's presence oversees both Mary's testimony and Sonny's belief formation and retention. Lackey and Pelling both assume this temporal order of events: Mary asserts at t1; Sonny forms a belief at t2; Frank silently monitors at T3; Sonny retains the belief at $\mathrm{t} 4$ - and Sonny's belief only becomes safe at 4 (Lackey, 2008, p. 82; Pelling, 2013, p. 211). But another understanding of the temporal order, I suggest, is this: Mary asserts at t1; also at $\mathrm{t} 1$ Frank is present and overhears what she says; Sonny forms his belief at $t 2 \ldots$ this belief is safe at the time it is formed because of Frank's silent contribution. But that very same contribution also assures that Mary's testimony is safe too - if Mary spoke falsely, Frank would immediately correct Mary, and she would retract her previous statement. 
One might object that given the definition of safe testimony that we are assuming, it seems that we have no choice but to consider Mary's testimony unsafe ${ }^{5}$. That is, recall that the relevant notion of safe testimony is this: 'Where one testifies that $p$ on basis $B$, one's testimony is safe just if there is no close possibility in which one falsely testifies that $p$ on $B$.' (Pelling, 2013, p. 209) So the fact that Mary would retract her statement if Frank had performed his milk dumping ritual and intervened does not help us, the objection continues. Mary would have asserted the same utterance on the basis of the same perceptual data, and in many of those nearby worlds her utterance is false. So her testimony is unsafe.

I submit that this objection presupposes an overly narrow conception of what counts as the basis for an assertion. Part of the aim of this paper is argue that we should not think of epistemic bases (for belief or assertion) too narrowly: we need to appreciate that external factors and an epistemically favorable environment are essential not only to knowledge generally, but also to testimonial knowledge in particular (see especially sections 4 and 5 below for the development of these points).

It is correct that the content of Mary's utterance, the proposition that there is milk in the fridge, while actually true, could have easily been false. But given the temporal order of the events I am considering, Frank is 'silently monitoring' the situation as Mary speaks. Had she spoken falsely, the utterance would not have been left to stand. So when Sonny forms his belief that there is milk in fridge, on the basis of his mother's standing assertion, given the presence of his uncle, that particular speech act could not have easily been false, given its basis (construed broadly as including not only the perceptual data Mary has to go on, but also including Frank's silent contribution). In short, if we allow that Frank's presence is able to make

\footnotetext{
${ }^{5}$ Thanks to anonymous referee for pressing me to consider this objection.
} 
Sonny's belief safe, it is open for us to hold that it also makes Mary's testimony safe. Frank's presence oversees both Mary's testimony and Sonny's belief formation and retention.

So Goldberg does not provide a case of safe belief based on unsafe testimony: either as I have suggested Mary's testimony and Sonny's belief are both safe, or as Lackey and Pelling argue, Sonny's belief is unsafe, or if his belief is safe, it is not wholly based on testimony, in the strict sense that we are considering.

Goldberg (2007) offers a second example that purports to also show that testimonial knowledge through unsafe testimony is possible:

Goldberg's Second Case - YANKEE FAN: When Ralph reads in the newspapers that his beloved New York Yankees have won, he bases his testimony about his team on those newspaper reports. When the newspapers report that the Yankees have lost, however, Ralph cannot bring himself to accept what he reads, and he bases his testimony instead on wishful thinking. But a curious feature of Ralph's testimony is that whenever it is based on newspaper reports, he speaks noticeably more confidently than he does when his testimony is based on wishful thinking. Joan is well aware of this tendency of Ralph's and as a result, she only accepts his testimony when he speaks confidently. The Yankees play and though they might easily have lost, they win. Ralph reads about their victory in the newspapers, and confidently tells Joan that they won. Joan accepts his testimony. (Pelling 2013, p. 212; Goldberg 2007, p. 322)

Commenting on the case, Goldberg says that Ralph's testimony is unsafe, since the Yankees could have easily lost, and if they had, Ralph would still have testified that they had won on the basis of his wishful thinking. Goldberg maintains that Joan's belief is safe, however, since if Ralph had falsely said that they had won, she would not have accepted his testimony, as his assertion would have been made noticeably less confidently.

I shall offer two objections to this case. First, like the second interpretation of Sonny's belief above, it seems that Joan's belief is not wholly testimonial. While it is certainly partly based on the content of Ralph's assertion, notice that Joan accepts 
Ralph's assertion not on the basis of his say so alone, but on the basis of his testimony, plus the fact that he asserted confidently, plus her knowledge that how confidently Ralph asserts something is a reliable indicator that what he says is true (which is not itself testimonial). Just as Sonny's safe belief above was not wholly testimonial given his uncle's epistemic contribution, so too is Joan's belief not wholly testimonial, given that it depends for its epistemic credentials on non-testimonial factors.

Second, why think that Ralph's testimony is unsafe? It is important to see that given its basis, his testimony could not have easily been false, given the general reliability of the newspapers reporting the sports results ${ }^{6}$. Accordingly, this seems analogous to a case of evidential luck, and such luck does not undermine safety or knowledge ${ }^{7}$. Evidential luck, as it applies to beliefs, is when one is lucky to have the evidence one does, but given that one has the evidence, it is not lucky that one's belief is true. For example, suppose one just happens to see a poster advertising a play reading that night - one very easily could have missed the poster, and so would not have formed a true belief. Nevertheless, despite the presence of this kind of luck, one does know that there is a play reading that night on the basis of luckily seeing the poster. Given that one did see the poster, and given that it was reliably created, and given that the play reading could not easily have been cancelled etc., one's belief could not easily have been false. As this example shows, such luck is compatible with knowledge.

Veritic luck, by contrast, arises when even given how a belief is formed, it could have very easily been false. For example, suppose a printer malfunctioned and

\footnotetext{
${ }^{6}$ In objecting to Goldberg's case, Pelling also suggests that Ralph's testimony is in fact safe, given its basis (Pelling asks us to assume that since the newspapers Ralph reads are carefully edited, there is no close possibility in which they contain a misprint); Pelling (2013), pp. 212-213.

${ }^{7}$ See Pritchard (2005) for a detailed articulation of the distinction between veritic and evidential luck, given in the course of developing and defending an anti-luck epistemology.
} 
randomly produced a date and time on a poster that advertised a play reading, and as it happened, there was a play reading at the time and day advertised. Unaware of all this, suppose that one saw the poster, and on the basis truly believed that there was a play reading that night. Here one's true belief is unsafe and does not amount to knowledge. It seems that this is due to the presence of vertitic luck: given how one's belief was formed, it could have very easily been false (namely in all the close worlds where the wrong date and time were randomly printed on the poster).

Returning to the case of Ralph with this distinction in hand, but applying it to testimony, we can see that his testimony is safe. Given its basis, Ralph's testimony could not have easily been false, given the general reliability of the newspapers reporting the sports results. While there is a sense in which it is lucky that his testimony is true, this is a benign kind of evidential luck that does not undermine safety.

Sensitive to these kinds of issues, Goldberg claims that Ralph's testimony is not safe, but he makes no claims about whether the belief Ralph expresses in the testimony is safe (Goldberg, 2007, p. 323). But as Pelling notes, Goldberg must assume that safe testimony does not relativize to safe bases in the way that safe belief does, but no explanation of this alleged difference is given in his paper (Pelling, 2013, p. 213) $)^{8}$. But this is a mistake. As I illustrated above, the evidential vs. veritic luck

\footnotetext{
${ }^{8}$ An anonymous referee for this journal rightly noted that Goldberg (2007) defers to Lackey (then forthcoming; now Lackey (2006)) for the claim that 'it is the safety of the testimony, rather than that of the belief manifested by the testimony, that is relevant to the epistemic status of the hearer's belief formed through accepting the testimony.' (Goldberg, 2007, p. 323) Accordingly, one might think, different conditions of safety apply for belief and testimony.

First, my concern here is specifically whether or not safe testimony relativizes to bases in the way that safe belief does, regardless of other sorts of differences that there might be between the safety of belief and testimony. As Pelling and I note, Goldberg (2007) provides no argument that safe testimony should not be relativized to bases in the same way as safe belief. So as Pelling suggests, given that this is essential to Goldberg's example, the onus is on him to explain why there should be this disanalogy between belief and testimony. But in addition to the issue of the burden of proof, I have directly argued that it is a mistake to hold that safe testimony should not be relativised to bases.
} 
distinction seems to apply just as much to testimony as it does to belief, and so safe testimony needs to be relativized to bases just as belief does.

So given that Joan's belief is not wholly based on testimony, in the strict sense that we are considering, and given that Ralph's testimony is not unsafe, given its basis, YANKEE FAN is not a case of safe testimonial belief based on unsafe testimony.

\section{Pelling's Example}

Aiming to provide a counterexample of his own to the view that safe testimonial belief requires safe testimony, Charlie Pelling provides an example that he claims avoids the dilemma facing Goldberg's examples. The following example is presented as one where the speaker's testimony is unsafe, the hearer's belief is safe, and the hearer's belief is presented as being wholly based on testimony:

TERRITORIAL FARMER: Farmer Fred is highly territorial. He worries continually that Randy may be trespassing on his land. Fred hears a rustle in the bushes. In his agitated state of mind, he jumps straight to the conclusion that it was Randy who made the rustle. On that basis, Fred shouts 'Randy, you're trespassing on my land'. Although the rustle might easily have been made by something else (there are many wild animals in the area), it so happens that Randy did make the rustle and he is indeed trespassing on Fred's land. On hearing Fred's words, Randy comes to believe that he is trespassing on Fred's land. (Pelling, 2013, p. 213)

Pelling says that the key to making this an example of safe testimonial belief based on unsafe testimony is to fill out the details as follows: 'the range of Fred's land extends much further than the carry of his voice.' (original emphasis) (Ibid. p. 214) This ensures that in all cases where Randy hears Fred's words, and so comes to believe that he is trespassing on that basis, he is indeed trespassing.

As I illustrated above, the evidential vs. veritic luck distinction applies just as much to testimony as it does to belief. 
A first question about the case: is Fred's testimony unsafe? Pelling argues that it is: there are many nearby worlds where the rustle is made by something other than Randy, such as wild animals, and Fred makes the same assertion, but it is false. In those worlds the rustle is made by something other than Randy, and Randy is not trespassing. A second question about the case arises: is Randy's belief safe? The answer, Pelling argues, is yes. He explains:

[...] in any of the close possibilities where Randy believes, on the basis of Fred's words, that he is trespassing on Fred's land, Randy is indeed trespassing: if he had not been trespassing, he would not have been able to hear Fred and hence would not have been able to form any belief on the basis of his words. (original emphasis) (Ibid.)

As for the third question which would establish if this is a genuine counterexample, is Randy's belief based wholly on Fred's testimony? Here too, Pelling suggests, the answer is yes: 'the only possible source from which Randy's belief can gain its epistemic credentials is Fred's testimony.' (Ibid. p. 215) If we grant that Fred's testimony is unsafe, and Randy's belief is both safe and wholly based on it, we then have a counterexample that proves the possibility of safe belief though unsafe testimony. This, in turn, would go some way to establishing that testimonial knowledge is possible on the basis of unsafe testimony.

So, is TERRITORIAL FARMER a successful counterexample? I suggest that it is not, and in fact, upon closer inspection, it shares the same defects as Goldberg's examples. In answering the second question, of whether Randy's belief is safe, it is important to see that it is only safe if we individuate the basis of his belief very widely, including not just the assertion, but all the surrounding circumstances as well that make an essential epistemic contribution. If we individuate the basis of Randy's belief very narrowly, holding that the basis of his belief is only Fred's statement, then Randy's belief is unsafe. This is so since there are nearby worlds where for example, 
Fred makes the same assertion from other parts of his property and his voice carries over the property line to where Randy is standing, and he forms the false belief that he is trespassing. Randy's belief is only safe on assumption that the 'same basis' includes holding fixed not only Fred's testimony, but also Fred's and Randy's relative locations, the volume of Fred's voice etc. In that case Randy's belief is not purely testimonial; if Randy's belief is based only on Fred's words, then Randy's belief is unsafe.

One might object that this argument assumes an odd conception of an epistemic basis, such that the basis of a belief must include everything that occurs in nearby possible worlds. ${ }^{9}$ For example, if $\mathrm{Al}$ believes that 'here is a mug', the laws of logic and events that occurred 5000 years ago are plausibly not thought to be part of the basis of Al's belief, even though these truths are kept fixed in all nearby worlds. Likewise, one might object, facts about Fred's and Randy's relative locations, the volume of Fred's voice etc., should not be counted as part of the basis of Randy's belief, despite the fact that they may be modally robust features in nearby worlds. Since they are not part of the basis of Randy's belief, his belief can be based solely on testimony and nonetheless be safe.

This much is correct: the laws of logic and events that occurred 5000 years ago are not part of the basis of Al's belief. Rather, these things are kept fixed in all nearby worlds because they are modally robust features of the actual world. The reason they are not part of the belief's basis, however, is that they make no direct contribution to that belief's epistemic credentials. Al's belief that 'here is a mug' depends for its epistemic credentials on his perceptual experience (or whatever it might be), not in any way at all on the laws of logic or events in the ancient past. Had

\footnotetext{
${ }^{9}$ Thanks to an anonymous referee for raising this objection.
} 
events in the ancient been different, presumably that would make no difference to the justification Al has for his mug belief. Randy's belief that is he trespassing, by contrast, does essentially depend for its epistemic credentials on the non-testimonial facts of the speaker and hearer locations, the volume of the speakers voice, and so on. Without these facts obtaining, his belief would not be safe. Therefore, as these facts make an essential epistemic contribution, they need to be included as part of the basis of his belief.

What this points to is that in order for Randy's belief to be safe (and potentially a case of knowledge), it depends on non-testimonial features. In response to the third question above, of whether Randy's belief is based wholly on Fred's testimony, Pelling insists that 'the only possible source from which Randy's belief can gain its epistemic credentials is Fred's testimony.' It is correct that Randy's belief is not just causally dependent upon Fred's testimony, like in Audi's case of someone who believes that the speaker has a soprano voice on the basis of her asserting that she is a soprano in a soprano voice (Audi, 1997, p. 420; Lackey, 2008, p. 42). In the soprano case, the content of the assertion is irrelevant - by knowing what a soprano sounds like, the hearer could come to truly believe that the speaker is a soprano, without even understanding the content of what is said. In Pelling's case, however, the content of Fred's assertion is relevant: Randy believes what he does because he understands the content of what is said.

But because Randy's belief is in that sense based on Fred's testimony, it does not follow that it is wholly based on it. Recall that in the context of this discussion, a belief does not count as testimonial if though casually dependent on an act of testimony, it depends for its epistemic credentials on something non-testimonial. While the notion of 'epistemic credentials' is somewhat unclear, I take it to refer to a 
belief's positive epistemic status, such as its justification, or whether it amounts to knowledge. If Randy's belief is knowledge, then one of the things that the state's epistemic properties depend upon is its modal robustness, and this in turn depends on things other than Fred's words. Safety is plausibly understood as an 'epistemic credential', as it is a positive epistemic status, and given that it is necessary for knowledge. But whether or not Randy's belief is safe depends not only on Fred's testimony, but also upon the location from which Fred's assertion is made, as well as Randy's location, the volume at which the assertion was made, etc. But facts like the locations of speakers and hearers are not themselves part of an assertion.

So Pelling's example shares the same defect as Goldberg's MILK CARTON: given the strict notion of testimonial belief at play, answers to Questions 2 and 3 cannot both be 'yes' simultaneously: either Randy's belief is unsafe if it is based solely on Fred's words, or if his belief is safe, it is not wholly based on Fred's testimony, but depends for its epistemic credentials on non-testimonial factors.

\section{Conclusion:}

Given the above discussion, a perhaps surprising question now emerges: is there any knowledge that is purely testimonial? To be sure, we need to be clear on what is meant by a belief being based wholly on testimony. But if one is maximally strict, following Lackey and Pelling, is there any purely testimonial knowledge? In other words, given the distinction drawn above between Strict and Liberal conceptions of testimonial belief, we can ask: assuming the Strict Conception of Testimonial Belief, is there any testimonial knowledge?

In light of the discussion of TERRITORIAL FARMER, my hypothesis is that, assuming the Strict Conception of Testimonial Belief, it is impossible to have a case 
of safe belief based solely on unsafe testimony. A testimonial statement just is not the kind of thing that can, all by itself, ensure that all the 'epistemic credentials' for knowledge are met. This is on the assumption that knowledge requires safety, and that safety is a matter of modal robustness. Such modal properties are essential to the epistemic credentials of the belief, but they cannot be ensured solely by the belief being based on a testimonial statement. Doing so also requires that various nontestimonial facts obtain.

Acknowledging that there may not be any purely testimonial knowledge, in the sense required by the Strict Conception of Testimonial Belief, in no way detracts from the importance and ineliminability of testimony as a source of knowledge. It means only that we need to accept a Liberal Conception of Testimonial Belief. Doing so also requires that we need to broaden our conception of what counts as an epistemic basis. There is more to being an epistemic basis than being a reason or a piece of evidence that a subject might consciously appeal to if challenged in defense of their belief. What the above discussion seems to show, is that when it comes to making determinations about the presence of testimonial knowledge, we need to look beyond the speaker's assertions and the internally accessible evidence that a hearer might have regarding the reliability and truthfulness of the speaker ${ }^{10}$.

What cases like TERRITORIAL FARMER and MILK CARTON point to is that factors like features of the external environment, or a third-party's so-called silent monitoring, can become part of the epistemic basis of belief. Given developments in extended cognition which hold that some mental processes can extend beyond the body to include aspects of the environment (e.g. Clark and Chalmers 1998), perhaps this is to be expected. In short, I hope my discussion has highlighted that we should

\footnotetext{
${ }^{10} \mathrm{I}$ am not the first to make this point. For example, see Riggs (2009), especially pp. 211-214; see also Greco (2016), especially 494-496.
} 
not think of epistemic bases too narrowly: we need to appreciate that external factors and an epistemically favorable environment are essential not only to knowledge generally, but also to testimonial knowledge in particular.

Suppose one accepts that we need to allow for a broader notion of testimonial belief, which is to say, endorse the Liberal Conception of Testimonial Belief. But recall that if we allow a broader notion of a belief being based on testimony, so that it is a matter of a belief being based on testimony plus non-testimonial features, then the answer to our question becomes straightforward: obviously knowledge is possible on what would have been an unsafe basis, but for the fact that additional elements conspire to make the testimony plus non-testimonial features a safe basis. On a broader conception of testimonial belief, the threat to the natural thought that safe testimonial belief requires safe testimony, from interesting putative counterexamples like Goldberg's and Pelling's, disappears.

Here are two further cases by way of illustration:

FBI PROFILER: Hanibal has true beliefs about the location of several victims that have been abducted by a deranged serial killer. He is also a pathological liar and will lie about the location of the victims as often as not. If he were to assert truly where a victim was being held, a hearer could not on that basis know where the victim is (although she might gain a true belief about the victims' whereabouts).

But suppose that knowing of Hanibal's unreliability as a source, an FBI profiler is brought in. She discovers through close examination, that unbeknownst to Hanibal, when, and only when, he tells the truth his pulse quickens. Clearly, Hanibal is in danger of speaking falsely - while what he says on a given occasion may be true, there are many nearby worlds where his assertion is false. He is unreliable and his assertions are not safe. Nevertheless, Hanibal asserts that the first victim is in an abandoned well; his pulse quickens accordingly. The hearer, who in this case is the FBI profiler with knowledge of the connection between the pulse rate and the content of what is said, can come to know that victim is in the well. From the testimony of the unreliable source, a reliable receiver of truths can acquire knowledge. It is not necessary that the speaker be a reliable source of information.

Is the FBI profiler's belief testimonial? It is based on Hanibal's testimony, and that testimony is not only causally relevant to what is believed. But the belief is not purely testimonial according to the Strict Conception of Testimonial Belief. The 
reason the profiler has knowledge is that her belief is based on three things: it is based on testimony, plus her belief that Hanibal's pulse quickening is a reliable indicator that he is speaking truly, as well as her observation that his pulse quickens. So the profiler's knowledge is testimonial only on the Liberal Conception of Testimonial Belief.

Consider one last similar case:

CARD SHARK: Alex is a skilled card shark and he wants to take the house. He scopes out the casino and spots an inexperienced, incompetent dealer. The dealer is utterly unreliable in reporting what hand he has been dealt: as often as not he will falsely report his hand. If he were to assert truly what hand he had been dealt, a hearer could not on that basis know his hand (although she might gain a true belief about the dealer's hand).

Suppose that discovering the dealer's weaknesses, Alex studies him carefully, and being an expert card shark, comes to realize that the dealer has a subtle tell: when, and only when, he has a high hand, he bites his lower lip. Clearly, the dealer is in danger of speaking falsely while what he says on a given occasion may be true, there are many nearby worlds where his assertion is false. He is unreliable and his assertions are not safe. Nevertheless, the dealer asserts that he has a full house; he proceeds to bite his lower lip. The hearer, who in this case is our card shark Alex with knowledge of the connection between the dealer's biting his lower lip and the dealer's assertions, can come to know that the dealer has a full house. From the testimony of the unreliable source, a reliable receiver of truths can acquire knowledge. It is not necessary that the speaker be a reliable source of information.

Is the card shark's belief testimonial? Again, it depends on whether we adopt a strict or liberal conception of testimonial belief. It is based on the dealer's testimony, and that testimony is not only causally relevant to what is believed. But the belief is not purely testimonial in Lackey and Pelling's strict sense. The reason the card shark has knowledge is that it based on testimony, plus the card shark's belief that the dealer's tell is a reliable indicator that his is speaking truly, as well as the observation that the dealer is biting his lower lip.

One might object that FBI and CARD SHARK are not relevantly similar to Goldberg and Pelling's cases ${ }^{11}$. After all, in both my cases, what renders them not 'purely' testimonial is the fact that the hearer has to actively engage in inference, and

\footnotetext{
${ }^{11}$ Thanks to Axel Gelfert for raising this objection.
} 
they draw on knowledge of circumstances external to the testimony. It is only on that basis that they correctly infer which subset of testimonial claims is reliable. But in Goldberg and Pelling cases, the hearer can be blissfully unaware of the external circumstances that, in fact, contribute to the safety of his (partially) testimonial belief.

In response, I shall argue that these are not relevant differences. My proposed cases are relevantly similar to Goldberg and Pelling's cases: they at first blush might appear to be cases of testimonial knowledge based on unsafe testimony. But in all these cases, mine and those offered by Goldberg and Pelling, the hearers do not gain pure testimonial beliefs, since their beliefs depend for their epistemic credentials on something non-testimonial -- though it is granted these non-testimonial features vary. In Goldberg's MILK CARTON case, the partially non-testimonial basis of Sonny's belief is the presence of a third party who will correct the speaker if she speaks falsely. In the YANKEE FAN case, like my two cases which rely on inference from background knowledge, Joan bases her belief not just on Ralph's testimony alone, but also on her knowledge that he is asserting confidently, and also her knowledge that his asserting confidently is a reliable indicator that what he says is true. YANKEE FAN, like my two cases, involves combining the speaker's testimony with inductive evidence correlating signs with truthfulness. In Pelling's TERRITORIAL FARMER case, it is non-testimonial facts about speaker and hearer locations, the relative volume of the speaker's voice etc. that are needed to fix the modal facts required for safety.

In YANKEE FAN, and my two cases, the hearers are, or easily could be, aware of the non-testimonial factors that contribute to the safety of their belief. Whereas in MILK CARTON and TERRITORIAL FARMER, these factors are outside the hearers' ken. Despite these differences, what all these cases have in 
common is that the hearers' belief, if safe, is not purely testimonial in the strict sense: their beliefs essentially depend for their epistemic credentials, at least in part, on something non-testimonial.

I have argued that, given the Strict Conception of Testimonial Belief required to generate the potentially important and novel philosophical results that Goldberg and Pelling aim to establish, it is impossible to have testimonial knowledge in that strict sense that is based on unsafe testimony. On the other hand, we can, and should, allow the Liberal Conception of Testimonial Belief. This is a broader notion of a belief being based on testimony, in that it is a matter of a belief being based on testimony plus non-testimonial features. But since an assertion is not the kind of thing that can, all by itself, ensure all the epistemic credentials for knowledge are met, knowledge based solely on unsafe testimony is impossible ${ }^{12}$.

\footnotetext{
${ }^{12}$ Thanks to Michael Brent, Constantine Sandis, and Alex Steinberg for helpful discussion. Thanks also to an audience at Lingnan University, Hong Kong for beneficial comments and questions (in particular, I recall helpful comments from Dan Marshall, Darrell Rowbottom and Bryan Frances). Thanks especially to (multiple) anonymous referees, Axel Gelfert, Guy Longworth, John Greco, and Rhiannon James for encouragement and helpful written comments on earlier drafts of this paper.
} 


\section{Sources Cited:}

Audi, Robert. (1997) 'The Place of Testimony in the Fabric of Knowledge and Justification'. American Philosophical Quarterly 34: 405-422.

Becker, Kelly. (2008) 'Epistemic Luck and The Generality Problem'. Philosophical Studies 139: 353-366.

Becker, Kelly and Black, Tim (eds.) (2012) The Sensitivity Principle in Epistemology. Cambridge: Cambridge University Press.

Beebe, James. (2004) 'The Generality Problem, Statistical Relevance, and the TriLevel Hypothesis'. Nous 38: 177-195.

Clark, Andy, and Chalmers, David. (1998) 'The Extended Mind'. Analysis 58: 719.

Comesana, Juan. (2006) 'A Well-Founded Solution to the Generality Problem'. Philosophical Studies 129: 27-47.

Conee, Earl and Feldman, Richard. (1998) 'The Generality Problem for Reliabilism'. Philosophical Studies 89: 1-29.

Dretske, Fred (1970). 'Epistemic Operators', Journal of Philosophy 67:24, 1007-23.

Gelfert, Axel. (2014) A Critical Introduction to Testimony. London: Bloomsbury.

Goldberg, Sanford. (2005) 'Testimonial Knowledge Through Unsafe Testimony'. Analysis 65: 302-311.

Goldberg, Sanford. (2007) 'How Lucky Can You Get?'. Synthese 158: 315-327.

Greco, John. (2016) 'What is Transmission*?'. Episteme 13: 481-498.

Heller, M. (1995) 'The Simple Solution to the Problem of Generality'. Nous 29: 501-515.

Hetherington, Stephen. (1998) 'Actually Knowing'. Philosophical Quarterly: pp. 453-469.

Hetherington, Stephen. (2013) 'Knowledge Can Be Lucky' in Steup M, Turri J,

Sosa E (eds.) Contemporary Debates in Epistemology, $2^{\text {nd }}$ ed. Wiley Blackwell: 164176.

Hetherington, Stephen. (2016) Knowledge and the Gettier Problem. Cambridge: Cambridge University Press.

Lackey, Jennifer. (1999) 'Testimonial Knowledge and Transmission'. Philosophical Quarterly 49: 471-490.

Lackey, Jennifer. (2006) 'Learning From Words'. Philosophy and Phenomenological Research 73: 77-101. 
Lackey, Jennifer. (2006) In Sosa \& Lackey (Eds.) The Epistemology of Testimony. Oxford: Oxford University Press.

Lackey, Jennifer. (2008) Learning From Words. Oxford: Oxford University Press. Madison, B.J.C. (2011) 'Combating Anti Anti-Luck Epistemology'. Australasian Journal of Philosophy 89: 47-58.

Nozick, Robert. (1981) Philosophical Explanations. Cambridge, Mass: Harvard University Press.

Pelling, Charlie. (2013) ‘Testimony, Testimonial Belief, and Safety'. Philosophical Studies 164: 205-217.

Pritchard, Duncan. (2005) Epistemic Luck. Oxford: Oxford University Press.

Pritchard, Duncan. (2007) 'How to be a Neo-Moorean' in Internalism and Externalism in Semantics and Epistemology, (ed.) S. Goldberg. Oxford: Oxford University Press.

Pritchard, Duncan. (2013) 'Knowledge Cannot Be Lucky’ in Steup M, Turri J, Sosa E (eds.) Contemporary Debates in Epistemology, $2^{\text {nd }}$ ed. Wiley Blackwell: 152-163.

Pritchard, Duncan. (2015) ‘Anti-Luck Epistemology and the Gettier Problem’. Philosophical Studies 172: 93-111.

Riggs, Wayne. (2009) 'Two Problems of Easy Credit'. Synthese 169: 201-216.

Sosa, Ernest. (1999) 'How to Defeat Opposition to Moore'. Philosophical Perspectives 13: 141-154. 